\title{
Brain Drain and Management Countermeasures in Small and Micro Enterprises
}

\author{
Yan Wang ${ }^{1}$ \\ ${ }^{1}$ Xi'an Iternational University; Xi'an, Shaanxi, 710077 \\ 59624917@163.com
}

Keywords: Brain Drain; Small and Micro Enterprise Talent Management

\begin{abstract}
In a market where economy increasingly competitive environment, talent has become the core business of their development and to enhance the competitiveness of the self, the competition between enterprises also translate into talent competition, especially small and micro enterprises. Small and micro enterprises are still in its infancy stage of development and in many internal conditions are not ideal, the personnel is an important factor in its development. Etc. This paper studies the brain drain and small businesses to manage content, in order to help small and micro enterprises to better retain talent and better self-development.
\end{abstract}

\section{Introduction}

According to the report on small and micro enterprises brain drain of our country can be seen in the recent announcement of the brain drain problem is not a few companies, but has become a common concern of small and micro enterprises and the urgent need to address the problem. In 2010, the wastage rate of small and micro enterprises reached about 20\%, including some important senior management and technical personnel to master the core [1]. In today's increasingly competitive and retain qualified personnel, a reasonable management measures brain drain has become very necessary.

\section{Brain Drain Impact on Small and Micro Enterprises}

Increase the Cost of Small and Micro Enterprises. When companies recruit a new employee, you need to be trained to enable them to be more in line with the needs of enterprise development, the development of enterprises out of a force. If the name of employee turnover, training costs of enterprises that invested in his possession, time costs, economic costs will be subject to varying degrees of damage. And this staff to leave, no longer bring economic benefits for the enterprise, companies need to make other people to his place, which increases the company's emergency response costs.

The employees after the loss associated with customers, technology management will be subject to different degrees of damage. Enterprise is in order to regain or re-train a substitute for the loss of employees who require additional costs to pay more. If the small and micro enterprises do not manage their timely turnover, will affect the stability of the team, the development of enterprises is very negative.

Reduce the Competitiveness of Small and Micro Businesses. After staff turnover, it will inevitably leak trade secrets and core technology of small and micro enterprises, thus taking the company's clients, to the enterprise caused losses underestimated [2]. If this mastering the core technology business trade secrets or employees poached by competitors, companies will face a huge competitive edge. Some also mastered the core technology of trade secrets and staff will start all over again, so that enterprises lose the original competitive advantage. These staff will dig even original enterprise is an important customer, it has become a new competitor companies. In any event, the competitiveness of enterprises will get dropped, will no longer have the original competitive advantage.

Affect the Normal Operation of Small and Micro Businesses. After a number of senior managers and senior technicians staff turnover, businesses can not find in a short time can reinforce 
its position in the staff. Even if able to timely find, but new employees need some time to re-adapt enterprise system and the environment, which affect the normal operation of the enterprise how many will even impose a fatal blow.

\section{The Reason Small Businesses Brain Drain}

Working Conditions. The reason is not only affected by the brain drain of wages, but also includes their work environment, the development prospects and business opportunities for their own development [3]. During the work, the employee will be combined with the company's own situation, develop appropriate career development plans. As competition from low-level jobs rose to senior jobs, there are shifting from simple boring work complex but challenging work, the work environment is not like turning like work environment. If companies can not meet the staff of these programs, then the employee will be achieved through separation or quit.

According to the latest data of the discovery, offered former employees is generally higher quality of the staff. This type of staff quites seriously to achieve self-worth, hope I can continue to grow with the business and development, they pursue not a stable job, but a self lifelong career [4]. Therefore, in order to constantly improve their ability to enhance self-worth, this type of staff will be reasonable analysis of the current state of development of enterprises and their own career development plan in line with the degree, if they meet the degree is not high, they will turn to new working conditions better business. Therefore, this type of turnover and the biggest, but it is in constant flow to achieve self-worth.

The Reason Work Relationships. Many staff turnover represents, not because less money, but because the heart is tired. Today, all companies in the same industry composition and amount of salary are similar, but the wastage rate of enterprises still high. The reason, as its main reason employee interpersonal relations, interpersonal problems have mainly come from their superiors and colleagues. Some bosses too have a sense of responsibility, supervision and staff unavoidably, so that employees do not have the opportunity to display their talent, can only do it in accordance with their say. So you stifle the creativity and enthusiasm of the staff work, so employees do not work a sense of accomplishment, it will go on day after day, feel that their ability will be wasted away. And some grandiose boss, subordinates afraid to surpass themselves, does not give the opportunity to show subordinates, not subordinate to seek proper benefits. Over time, employees will eventually think he did not receive due attention and respect, and my heart will feel wronged, such negative emotions accumulated to a certain extent, the outbreak will eventually lead to exercise our powers to leave.

Man-machine relationship between colleagues and are more concerned with a corporate culture. Some corporate culture is not good, like my colleagues to engage in small teams, which seriously undermines the solidarity and stability of the corporate team. For the "outside the team," the staff were isolated, disguised attack, so that employees do not normally carry out their work, over time will naturally take the resignation of ways to escape such a "dangerous place."

Management and Development of Enterprises. Management and development company with its own visibility, management and enterprise scale are of great relevance, but the small and micro enterprises in these three areas are not dominant [5]. Almost all of the small businesses there are a variety of management issues, such as working time is unreasonable, wage structure is not standardized. When companies do not address these issues in a timely manner, the staff will feel they have been unfairly treated, over time it is easy for companies liter dissatisfied heart, until the right opportunity will naturally leave the business.

Work standards are artificially small and micro businesses decide, whether standards are too high or too low will affect the enthusiasm of the staff. Too, because of its own staff can not reach, easy to form frustration, when this feeling did not receive timely troubleshooting will blow their work enthusiasm. Too low, employees will not get proper sense of accomplishment and a sense of accomplishment, I feel even the lack of their own, companies will not suffer any loss, resulting in increasing employee no motivation, self-development ability of enterprises have also been limitations. When companies do not have enough self-development capacity and competitiveness, 
will not be able to gain a foothold in the competitive market, it can not provide the necessary sense of security and a sense of belonging for the employees.

Employee Personal Reasons. Since the employee for personal reasons, unable to reach a consensus with the business, employees will choose to resign. In this type of staff, the probability of women resignation will be higher. Spouse because of work, or home for the elderly children need care and choose to resign. But after all, the reason for this kind resignation is not the majority, most employees still dissatisfied because the company meet their own career development, staff can not achieve a good self-worth.

Unprofessional Corporate Recruiters. Currently people have to go through a job interview business professional and recruiter before entering the company represents the company and personnel communication, communication, in order to reach an agreement. But some recruiters in order to complete the company's "recruitment mission", often excessive beautify their business, offering some of the conditions can not be achieved when the talent into the company and found that recruiters said and promised are not achieved and beyond their acceptable level, leading to a desired talent not realized, it will naturally choose to leave.

To the people to "company man," did was "stepping stone" role recruiters, more or depend on internal working atmosphere, its own development team building, employee development plans, performance appraisals and business and planning. The pilot training is not only an important part of corporate culture, but also new employees know the company's most important stage, the staff at this stage not only learned the inner workings of business rules and responsibilities, but also with older employees to communicate and understand each other, are team Key Construction. But many small businesses believe such training is not necessary, or just make it into a formalism and did not play the desired effect.

\section{Small and Micro Enterprise Talent Flow Management Strategies}

Colleague Exit Interviews, Analysis of the Main Reasons for Employee Turnover. Exit interviews are many large companies before leaving for staff will certainly do a job, not only in the interview business can once again retain staff, but also to understand the real cause of employee turnover, through the collection and analysis of these reasons, so as to formulate an effective prevention program [6]. Small businesses can also be used in this way, managers and former employees to conduct a profound interview, understand employee ideas for corporate, consult staff views on the enterprise. To be able to retain as much as possible to retain employees, to retain employees should not give the necessary help and blessing, and said that if employees can businesses welcome back again. As long as the leadership of the company to strengthen their own development capacity, based on the employees to give the necessary care and assistance, so that employees have a sense of belonging and a sense of security for businesses, employees will unswervingly closely aligned with the business.

Enhance Recruitment Professional Degrees. The brain drain pressure companies not to put all the recruiting department, but should allow recruiters to fully clear understanding of the type of talent that businesses need, targeted recruitment enhance the recruitment of talent retention. When the recruitment conducted successfully, small and micro enterprises to carry out the necessary training, should not the cost or anxious and skip this step. Throughout the recruitment process, candidates for enterprises have a comprehensive, in-depth understanding of business recruitment or personnel should be detailed, answer questions truthfully candidates concerns, deepen mutual understanding of each other, the recruitment success rate It will be higher.

Establish and Improve the Personnel Management System. Sound personnel management, including work norms and responsibilities, performance and competition liter system. Only employees understand their job specifications and responsibilities, in order to better understand and complete their work content. Improve system performance and competition liter can effectively motivate staff enthusiasm for work, to help employees better fulfill their own career planning, self-realization. In establishing a sound personnel management system, the framers to follow the 
principles of humanity, for the staff to create a good working environment, thus effectively reduces the staff mobility.

\section{Conclusion}

Important capital "people" has become a business, the development of enterprises needs people, the normal operation of enterprises also needs people. Faced with the high rate of brain drain, small and micro businesses need to think about not only how to recruit more talent, and how to cultivate a well kept "business people." Only by former employees every interview, in order to understand the business of talent management loopholes to carry out remedial measures and timely response; only clear the type of talent they need to build a team with enterprise centripetal force; only establish a sound management system, in order to for staff to create a good atmosphere for employees to achieve self-worth. Only the importance of "person" status in which, taking into account sound management system, small and micro enterprises in order to steady, gradual development.

\section{Reference}

[1] Xu Qiongjuan. Small And Micro Enterprise Human Resource Management Strategies - Retain Key Employees [J]. Yunnan TV University, 2012,02: 65-68.

[2] Wang Lanfen. Small and Micro Enterprises Staff Turnover and Management Strategies of Inquiry [J]. Baoding College, 2012,04: 63-65.

[3] Qian Hangdan. Small and Micro Enterprises High Staff Turnover Rate Factors Empirical Analysis once the Money Airlines [J]. Changzhou Institute of Technology, 2014,06: 53-57.

[4] Wang Hui. Small Brain Drain Status Quo, Incentives and Countermeasures [J]. Human Resources Management, 2014,04: 208-209.

[5] Qin Yi, Dai Dandan. Corporate Employee Loyalty and Turnover Analysis [J]. Productivity Research, 2014,06: 125-129.

[6] Jia Fang. Current Situation and Countermeasures Jia Aryl-Tech Small and Medium Micro Enterprise Knowledge Workers Management-Based on Psychological Contract [J]. Economics, 2014,04: 52-53. 